K. Groves, P. Titoria and W. Morley

\title{
Food innovation and nanotechnology—do they go together?
}

ABSTRACT. Innovation is the key to progression in any business and food is certainly no exception. In order to innovate successfully, the application of science and technology to practical matters is needed, and therefore it is important to keep in touch with new, emerging technologies and advances. Nanotechnology as a quintessential emerging technology can offer real benefits regarding innovation, both to the food industry and to the consumer. One might note that it is in fact not one technology but very many technologies with wide applications in all areas of life, not just foods. Nanotechnologies have controversial connotations with some consumers and the media are concerned about why the industry wants to use them and whether they are safe. This article presents a review of the potential applications of nanotechnologies in foods, discussing what is out there now as well as risks and benefits.

Nanotechnology Perceptions 7 (2011) 141-147

Nonsubscribers: purchase individual article 